\title{
Quantitative Trait Loci Analysis and Mapping of Seedling Resistance to Stagonospora nodorum Leaf Blotch in Wheat
}

\author{
Z. H. Liu, T. L. Friesen, J. B. Rasmussen, S. Ali, S. W. Meinhardt, and J. D. Faris
}

First, third, and fourth authors: Department of Plant Pathology, North Dakota State University, Fargo 58105; second and sixth authors: U.S. Department of Agriculture-Agricultural Research Service, Cereal Crops Research Unit, Red River Valley Agricultural Research Center, Northern Crop Science Lab, Fargo, ND 58105; and fifth author: Department of Biochemistry, North Dakota State University, Fargo 58105.

Accepted for publication 11 June 2004.

\begin{abstract}
Liu, Z. H., Friesen, T. L., Rasmussen, J. B., Ali, S., Meinhardt, S. W., and Faris, J. D. 2004. Quantitative trait loci analysis and mapping of seedling resistance to Stagonospora nodorum leaf blotch in wheat. Phytopathology 94:1061-1067.

Stagonospora nodorum leaf blotch is an economically important foliar disease in the major wheat-growing areas of the world. In related work, we identified a host-selective toxin (HST) produced by the $S$. nodorum isolate Sn2000 and determined the chromosomal location of the host gene (Snnl) conditioning sensitivity to the toxin using the International Triticeae Mapping Initiative mapping population and cytogenetic stocks. In this study, we used the same plant materials to identify quantitative trait loci (QTL) associated with resistance to fungal inoculations of Sn2000 and investigate the role of the toxin in causing disease. Disease reactions were scored at 5,7 , and 10 days postinoculation to evaluate changes in the degree of effectiveness of individual QTL. A major QTL was identi-
\end{abstract}

ABSTRACT

Stagonospora nodorum (Berk.) causes Stagonospora nodorum blotch (SNB), which is an important fungal disease of common wheat (Triticum aestivum L., $2 n=6 x=42$, AABBDD genomes) and durum wheat (T. turgidum L., $2 n=4 \times=28$, AABB genomes), and it occurs in major wheat-growing areas throughout the world (10). Because the pathogen can infect both seedlings and spikes, yield losses in wheat production can reach $50 \%$ $(16,22,52)$, and grain quality also can be affected (32). The pathogenic fungus was originally identified and classified as a Septoria sp. in 1850, but recently was moved to the genus Stagonospora. Also, the teleomorphic stage was transferred from Leptosphaeria to Phaeosphaeria (6).

Utilization of host resistance is considered to be the most important and preferred method to control disease. However, in the case of SNB, no immunity or complete resistance has been found in existing wheat germ plasm, and only partial resistance was identified in some wheat cultivars, lines, and related species $(10,52)$. The results from classical genetic analyses indicated that the inheritance of resistance to SNB is complex. Most studies suggest that resistance to SNB is governed by multiple genes $(3,8,16,46)$, whereas monogenic inheritance was found in some wheat materials $(23,29,35)$. Additive gene effects were most important, but sometimes nonadditive effects, epistasis, and dominant or partially dominant gene action also were detected $(8,34$,

Corresponding author: J. D. Faris; E-mail address: farisj@ fargo.ars.usda.gov

Publication no. P-2004-0816-01R

This article is in the public domain and not copyrightable. It may be freely reprinted with customary crediting of the source. The American Phytopathological Society, 2004 fied on the short arm of chromosome 1B, which coincided with the snn1 toxin-insensitivity gene. This locus explained $58 \%$ of the phenotypic variation for the 5-day reading but decreased to $27 \%$ for the 10-day reading, indicating that the toxin is most effective in the early stages of the interaction. In addition, relatively minor QTL were identified on chromosomes 3AS, 3DL, 4AL, 4BL, 5DL, 6AL, and 7BL, but not all minor QTL were significant for all readings and their effects varied. Multiple regression models explained from $68 \%$ of the phenotypic variation for the 5 -day reading to $36 \%$ for the 10 -day reading. The Chinese Spring nullisomic 1B tetrasomic 1D line and the Chinese Spring-Triticum dicoccoides disomic 1B chromosome substitution line, which were insensitive to SnTox1, were more resistant to the fungus than the rest of the nullisomictetrasomic and disomic chromosome substitution lines. Our results indicate that the toxin produced by isolate $\mathrm{Sn} 2000$ is a major virulence factor.

Additional keywords: disease resistance, Septoria, Triticum aestivum.
42). Resistance to SNB on leaves may be independent of resistance to SNB on spikes $(16,52)$.

The use of molecular markers for the construction of genetic linkage maps in segregating populations permits the estimation of the number, chromosomal positions, and degrees of effects of polygenes affecting quantitative trait loci (QTL). Molecular markers tightly linked to major QTL can be deployed for markerassisted selection (MAS). Messmer et al. (33) used 121 DNA markers to construct a preliminary genetic map and found seven QTL associated with resistance to leaf infection of SNB and seven QTL for spike resistance. Each of them explained 5 to $19 \%$ of the phenotypic variation, and only one QTL was common to both leaf and spike resistance. Recently, Czembor et al. (7) identified four QTL significantly associated with partial resistance to leaf blotch in a doubled-haploid population derived from a cross between the partially resistant 'Liwilla' and susceptible 'Begra'. The QTL were located on chromosomes 2B, 3B, 5B, and 5D. Schnurbusch et al. (45) detected QTL on 3BS, 4BL, and 5BL for Stagonospora glume blotch resistance in Swiss winter wheat. In durum wheat, two random amplified polymorphic DNA markers were found to flank the leaf blotch resistance gene $s n b T M$, which was introgressed from $T$. timopheevii and located on chromosome $3 \mathrm{~A}(4,29)$.

In the early 1990s, the International Triticeae Mapping Initiative (ITMI) mapping population was developed and used to construct molecular marker-based genetic maps of wheat. Dense genetic maps of all 21 chromosomes now exist and include hundreds of molecular marker loci $(31,39-41,43,51)$ (available online in the Graingenes database). Many major genes and QTL for disease resistance and agronomically important characters have been mapped in this population $(2,12,13,21,27,37,38,48,49)$. 
In closely related work, we identified a host-selective toxin (HST) produced by the $S$. nodorum isolate $\mathrm{Sn} 2000$ and designated it SnTox1 (28). We also determined that a single gene in the host confers sensitivity to SnTox1, which we have designated Snn1. Physical mapping using Chinese Spring cytogenetic stocks and genetic mapping using the ITMI mapping population revealed that Snnl lies near the tip of the short arm of chromosome 1B. Here, we report the identification of QTL associated with resistance to fungal inoculations of $\mathrm{Sn} 2000$ and investigate the role of SnTox1 in causing disease using the same materials.

\section{MATERIALS AND METHODS}

Plant material. The genetic mapping population consisted of 106 recombinant inbred (RI) lines (partial ITMI mapping population) derived from a cross between the synthetic hexaploid wheat W-7984 and the hard red spring wheat cv. Opata 85 (plant introduction no. 591776). The population was provided by M. E. Sorrells, Cornell University, Ithaca, NY. Development of this population was described in Nelson et al. (41). Wheat cytogenetic stocks, including nullisomic-tetrasomic (NT) lines (47) and Chinese Spring-T. dicoccoides (CS-DIC) disomic chromosome substitution lines, were screened to further evaluate the role of Snnl in causing disease. The NT lines have a pair of missing chromosomes that are partially compensated for by an extra pair of homoeologous chromosomes, and the CS-DIC lines have a pair of T. dicoccoides chromosomes substituted for a homologous pair of CS chromosomes. The CS-DIC lines were provided by the Wheat Genetics Resource Center, Kansas State University. The hexaploid wheat lines ND495, Erik, Kulm, BR34, and Grandin also were screened with the fungus and used as inoculation checks.

Fungal inoculation and disease ratings. Three replications were used for disease evaluation. For each replication, nine plants

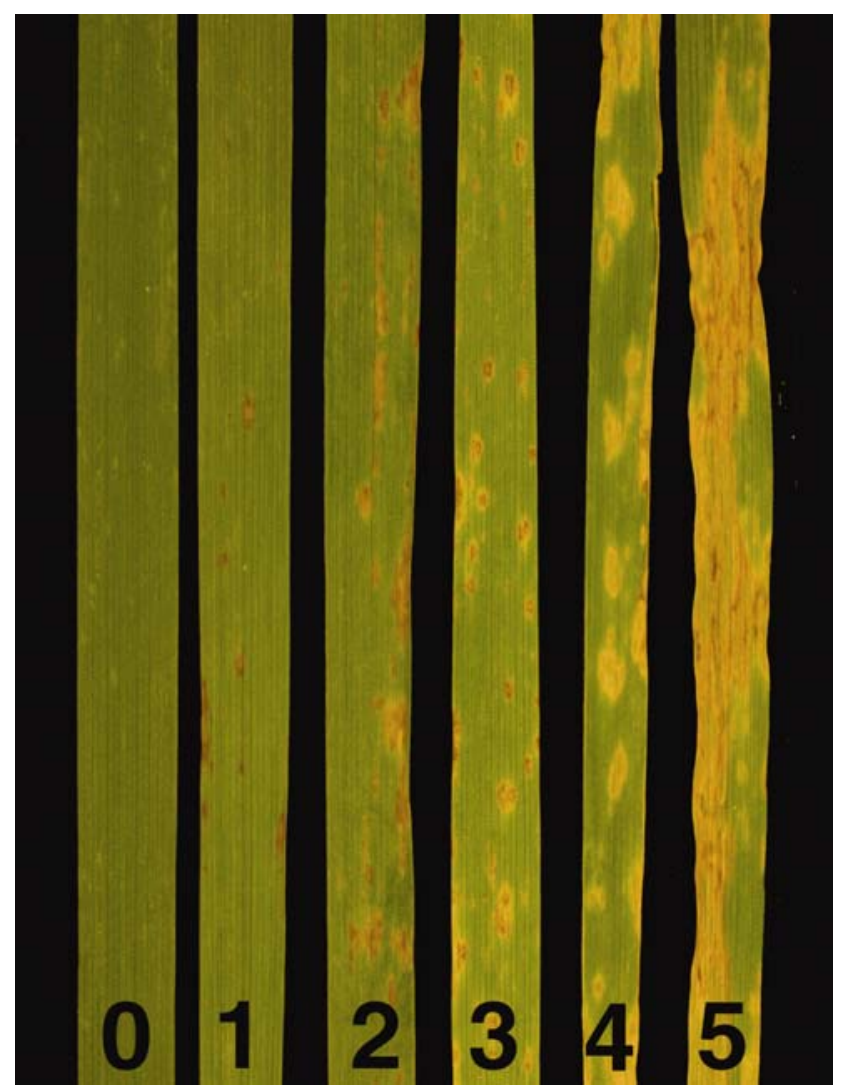

Fig. 1. Qualitative numerical (0-to-5) rating scale based on lesion type. Numbers at the bottom of leaves indicate the lesion types as defined in text. of each RI line, parents, and CS aneuploid lines were grown in cones with three individuals per cone. Cones were placed into racks of 98 bordered by the susceptible genotype ND495. All plants were grown in the greenhouse at an average temperature of $21^{\circ} \mathrm{C}$ with a $16-\mathrm{h}$ photoperiod. Plants were inoculated at the twoto three-leaf stage.

Isolate $\mathrm{Sn} 2000$ was grown on V8-potato dextrose agar (PDA) ( $150 \mathrm{ml}$ of $\mathrm{V} 8$ juice, $3 \mathrm{~g}$ of $\mathrm{CaCo}_{3}, 30 \mathrm{~g}$ of sucrose, $10 \mathrm{~g}$ of Difco PDA, $10 \mathrm{~g}$ of agar in $1,000 \mathrm{ml}$ of water) by spreading $200 \mu \mathrm{l}$ of pycnidial spores onto the plate using a sterile inoculating loop. Cultures then were grown for 7 to 10 days and plates were washed with sterile distilled water and further diluted to $1 \times$ $10^{6}$ conidia $\mathrm{ml}^{-1}$ for inoculations. Two drops of Tween 20 (polyoxyethylene sorbitan monolaurate) were added per $100 \mathrm{ml}$ of inoculum. Plants were inoculated until runoff. Following inoculations, plants were placed in a mist chamber at $100 \%$ relative humidity for $24 \mathrm{~h}$ in the dark, followed by incubation in growth chambers with a 12-h photoperiod and constant temperature of $21^{\circ} \mathrm{C}$ until evaluation.

Plants were scored for reaction to the fungus at 5, 7, and 10 days postinoculation. A 0 -to-5 qualitative lesion-type rating scale was used to evaluate each line, where $0=$ absence of visible lesions (highly resistant); 1 = few penetration points, with lesions consisting of flecking or small dark spots (resistant); $2=$ lesions consisting of dark spots with little surrounding necrosis or chlorosis (moderately resistant); $3=$ dark lesions completely surrounded by necrosis or chlorosis, lesions 2 to $3 \mathrm{~mm}$ (moderately susceptible); 4 = larger necrotic or chlorotic lesions $4 \mathrm{~mm}$ or greater, with little coalescence (susceptible); and $5=$ large coalescent lesions with very little green tissue remaining (highly susceptible) (Fig. 1). Plants having equal numbers of two different lesion types were given an intermediate lesion type (e.g., lesion types 1 and 2 equals 1.5).

Identification of the HST, SnTox1, and procedures for partial purification, infiltration, and analyses were reported by Liu et al. (28).

QTL analysis. The map used in this study employed 524 genetic markers. All maps and mapping data are available through the Graingenes website (which is a product of the U.S. Department of Agriculture-Agricultural Research Service). The 5-, 7-, and 10-day phenotypic averages of three replications were regressed on genotypic marker data to identify genomic regions associated with resistance. Simple linear regression was conducted using the computer program Map Manager QTXb20 (30) to identify markers associated with resistance at the 0.005 level of probability. Using this significance threshold on a data set of this size is likely to result in the identification of significant marker-trait associations by random chance. However, we chose the significance threshold of $P<0.005$ in order to reduce the risk of committing a type II error (declaring nonsignificance of a significant QTL). Simple and composite interval-regression (CIM) mapping (19) then was performed on chromosome linkage groups possessing markers with significant single-factor effects using a subset of the marker data set that consisted of 360 informative markers distributed approximately every 10 centimorgans along the chromosomes. To determine the critical logarithm of the odds (LOD) threshold, we executed a permutation test with 5,000 permutations. A LOD threshold of $\approx 3.0$ in this RI population yielded an experiment-wise significance level of 0.05 (26). Markers having significant main effects were tested against all other markers on the map to detect significant $(P<0.005)$ interactions. Significant markers and interactions were assembled into multiple regression models using the computer program QGENE (36). Markers that failed to retain significance in the model were eliminated. The coefficient of determination $\left(R^{2}\right)$ from the multiple regression model is the proportion of the total phenotypic variation explained by the markers. 


\section{RESULTS}

Symptomatology and scoring. All wheat genotypes, including parents and checks, were screened by inoculation with Sn2000 at the two- to three-leaf stage, and the second leaf was examined for disease reaction. Of the checks, only Erik and BR34 were highly resistant to Sn2000 (Table 1) and showed few lesions or small dark spots at the sites of infection indicating a resistant response. Kulm, ND495, Grandin, and CS were highly susceptible. The susceptible reaction of these genotypes developed very quickly, with lens-shaped necrotic and chlorotic lesions that became larger and coalesced as the disease progressed. Opata 85 and W-7984 showed reactions that differed from the resistant and susceptible checks and were considered moderately resistant to moderately susceptible (Table 1). The lesion types also differed between Opata 85 and W-7984. Opata 85 developed small, dark lesions surrounded by necrosis or chlorosis, but the lesions developed more slowly than the susceptible checks. W-7984 exhibited brown necrotic lesions without any chlorotic border throughout the leaf at 5 days after inoculation. As the disease developed, the necrotic lesions became darker and somewhat enlarged.

Although the two parental lines were moderately resistant to Sn2000, analysis of variance indicated highly significant differences among RI lines for reaction to $\mathrm{Sn} 2000$, and transgressive segregants were common, indicating that Opata 85 and W-7984 possess different resistance genes (Table 2; Fig. 2). The most highly resistant RI lines developed only small dark lesions similar to the resistant checks and were scored as lesion types 1 to 1.5 . The most highly susceptible lines developed large areas of necrosis or extensive chlorosis, and they had lesion types ranging from 3.5 to 4.5 . Over time, the lesion type means of the whole population increased from 2.18 at 5 days to 2.54 at 10 days (Fig. 2).

TABLE 1. Lesion types of parents and checks after inoculation of seedlings with conidia from isolate Sn2000 of Stagonospora nodorum

\begin{tabular}{lcccc}
\hline & & \multicolumn{3}{c}{ Lesion types $^{\mathrm{z}}$} \\
\cline { 3 - 5 } Genotype & Toxin reaction $^{\mathrm{y}}$ & 5-day & 7-day & 10-day \\
\hline W-7984 & $\mathrm{S}$ & $2.0 \mathrm{~d}$ & $2.2 \mathrm{~d}$ & $2.5 \mathrm{~d}$ \\
Opata85 & $\mathrm{I}$ & $2.5 \mathrm{c}$ & $2.6 \mathrm{c}$ & $2.8 \mathrm{c}$ \\
Erik & $\mathrm{I}$ & $1.2 \mathrm{e}$ & $1.2 \mathrm{e}$ & $1.5 \mathrm{e}$ \\
Kulm & $\mathrm{S}$ & $3.5 \mathrm{~b}$ & $4.0 \mathrm{~b}$ & $5.0 \mathrm{a}$ \\
ND495 & $\mathrm{S}$ & $3.5 \mathrm{~b}$ & $3.8 \mathrm{~b}$ & $4.5 \mathrm{~b}$ \\
BR34 & $\mathrm{I}$ & $0.0 \mathrm{f}$ & $0.0 \mathrm{f}$ & $0.5 \mathrm{f}$ \\
Grandin & $\mathrm{S}$ & $4.0 \mathrm{a}$ & $4.5 \mathrm{a}$ & $5.0 \mathrm{a}$ \\
CS & $\mathrm{S}$ & $4.0 \mathrm{a}$ & $4.5 \mathrm{a}$ & $5.0 \mathrm{a}$ \\
\hline
\end{tabular}

${ }^{\mathrm{y}}$ Reaction to a partially purified toxin produced by Sn2000; I = insensitive and $\mathrm{S}=$ sensitive.

${ }^{\mathrm{z}}$ Numbers followed by the same letter in the same column are not significantly different at $P=0.05$ based on a least significant difference test. Lesion types range from 0 (most resistant) to 5 (most susceptible).
We observed obvious differences between toxin-sensitive and -insensitive lines in disease severity. Most toxin-insensitive RI lines had disease reactions that ranged from 1 to 3 , and only 8 insensitive lines had lesion types greater than 3 for the readings taken 10 days after inoculation. The lesion types for most toxinsensitive lines were greater than 2 , and none of these were highly resistant (Table 2). Lesion type means were significantly different between toxin-insensitive and -sensitive lines for all three readings at 5,7, and 10 days postinoculation.

QTL analysis and mapping. The 5-day reading. Simple linear regression analysis of the 5-day reading data revealed eight genomic regions that contained markers significantly associated with the resistance to $\mathrm{Sn} 2000$ (Table 3). The toxin insensitivity locus (snnl) on chromosome 1B was the marker most significantly associated with the disease reaction. This locus explained $58.3 \%$ of the variation, indicating that insensitivity conferred by the snn1 allele from Opata 85 underlies a major QTL at 5 days after inoculation (Table 3; Fig. 3). An epistatic interaction between snnl and the marker Xmwg546 on chromosome 2B also was significant (Table 4 ) and explained $\approx 4.7 \%$ of the variation, but Xmwg546 itself was not significant (Table 3).

Markers Xcdo1312, XksuG12, Xksu912(Prp), Xcdo1508, Xbcd361, Xbcd758, and Xksu927(Grp94), which map to chromosomes 4BL, 4AL, 3AS, 5DL, 3DL, 6AL, and 7BL, respectively, were significant at $P<0.005$ and individually explained from 4 to $9 \%$ of the phenotypic variation (Table 3 ). With the exception of Xksu927(Grp94), the resistance effects at these marker loci were contributed by W-7984. Of these markers, only Xcdo1312 retained significance in the CIM analysis (Fig. 3) and the multiple regression model (Table 3 ). The multiple regression model consisted of the snnl locus on 1BS, Xcdol312 on 4BL, and the interaction between $X m w g 546$ and snnl, which together explained $68.2 \%$ of the total phenotypic variation.

The 7-day reading. The results of the 7-day reading revealed that the effects of the major QTL identified by the snn1 locus decreased and explained $48.0 \%$ of the variation (Table 3 ) compared with the $58.3 \%$ for the 5-day reading. The interaction between snnl and Xmwg546 retained significance at the 7-day reading and explained $6.4 \%$ of the variation compared with $4.7 \%$ at 5 days (Table 3 ). With the exception of Xksu927(Grp94) on 7BL, the six other marker loci associated with resistance to $\mathrm{Sn} 2000$ for the 5-day reading also were significant for the 7-day reading. Markers Xcdo1312, $X b c d 361$, and $X b c d 758$ had increased effects at the 7-day reading compared with the 5-day reading, and marker Xcdo1508 had a decreased effect, whereas markers XksuG12 and Xksu912(Prp) explained the same amount of variation for the 5-day and 7-day readings. As with the 5-day reading, only snn1 and Xcdol312 were significant in the CIM analysis for the 7-day reading (Fig. 3). The multiple regression model for the 7-day reading consisted of snn1, Xcdo1312, and the interaction between snn1 and Xmwg546, and it explained $62 \%$ of the phenotypic variation (Table 3 ).

TABLE 2. Distribution of lesion type means for the International Triticeae Mapping Initiative recombinant inbred (RI) population at 5, 7, and 10 days after inoculation with $\operatorname{Sn} 2000$

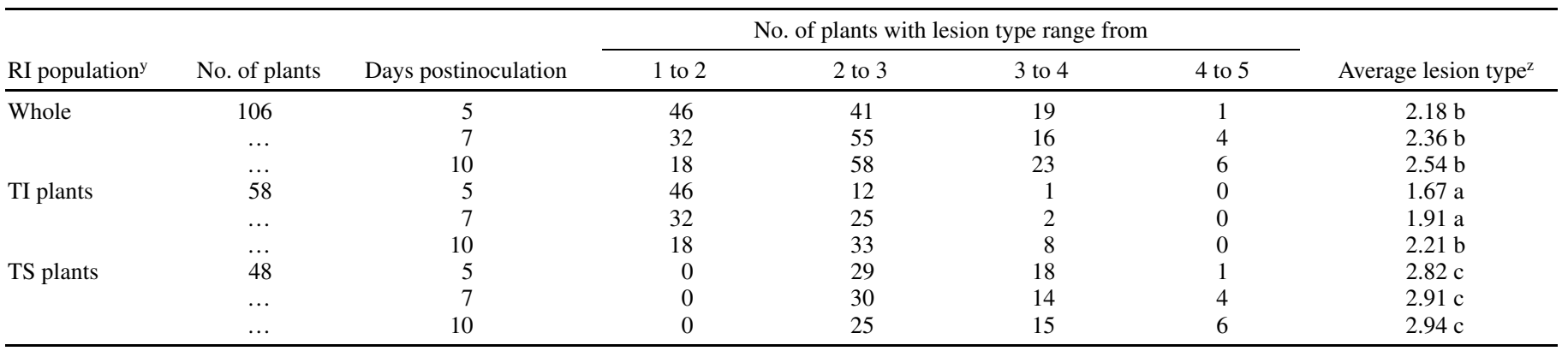

y Whole $=$ whole population, $\mathrm{TI}=$ toxin-insensitive plants, and TS $=$ toxin-sensitive plants.

${ }^{\mathrm{z}}$ Numbers followed by the same letter in the same column are not significantly different at $P=0.05$ based on a least significant difference test. Lesion types range from 0 (most resistant) to 5 (most susceptible). 
The 10-day reading. Analysis of lesion types 10 days after inoculation indicated that the effects of the snnl locus were significantly associated with resistance. However, the effects of this locus decreased compared with the 5- and 7-day readings and explained $27.3 \%$ of the phenotypic variation (Table 3 ). The effects of the 4BL locus detected by Xcdol312 decreased compared with the 7-day reading and explained $8.0 \%$ of the variation for the 10-day reading compared with $9.0 \%$ for the 7 -day reading. The marker XksuG12 on chromosome 4AL showed an increased effect at the 10-day reading and explained $7.0 \%$ compared with $4.0 \%$ for the 5- and 7-day readings. The effects of marker Xksu912(Prp) on chromosome 3AS did not change compared with the 5- and 7-day readings and explained $8.0 \%$ of the variation. Markers Xcdo1508 (5DL), Xbcd361 (3DL), and Xbcd758 (6AL), which were significant for the 5- and 7-day readings, were not significant for the 10-day reading. Xksu927(Grp94) on
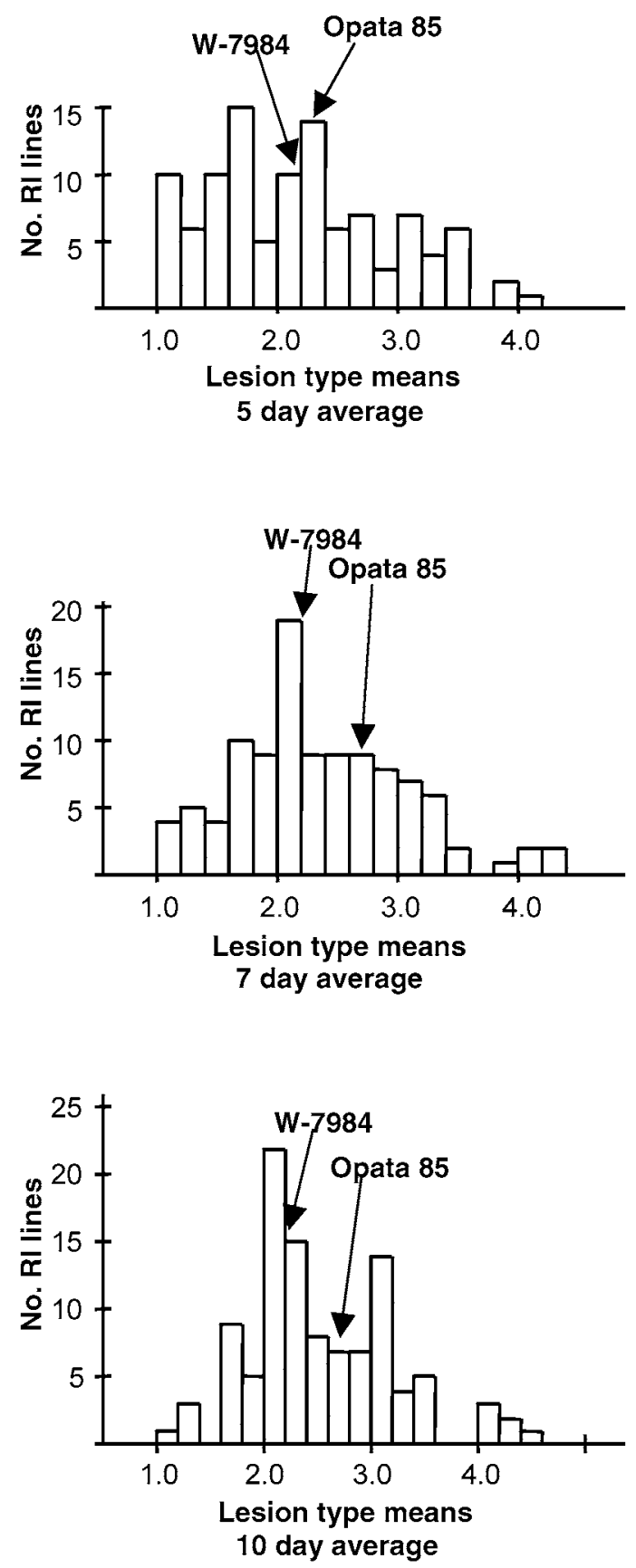

Fig. 2. Histograms of the International Triticeae Mapping Initiative population at 5, 7, and 10 days after inoculation with Stagonospora nodorum isolate $\operatorname{Sn} 2000$. chromosome 7BL, which was significant for the 5-day reading but not for the 7-day reading, was significant for the 10-day reading and explained $6.0 \%$ of the variation. Only the snnl locus on 1BS was significant in the CIM analysis for the 10-day reading. The multiple regression model for the 10-day reading consisted of snnl and Xcdol312 and explained 36\% of the total phenotypic variation.

Aneuploid analysis of fungal inoculation. The CS NT lines and CS-DIC substitution lines were screened for reaction to Sn2000. CS is highly susceptible (lesion types 4.0 to 5.0 ) and the $T$. dicoccoides accession used to create the disomic substitution lines is moderately resistant (lesion types 2.0 to 2.5 ). For the 5-, 7-, and 10-day readings, the toxin insensitive line N1BT1D had mean lesion types of 3.0, 3.5, and 4.5, respectively, and insensitive CS-DIC $1 \mathrm{~B}$ had mean lesion types of 3.0, 3.5, and 4.0, respectively. The rest of the NT and CS-DIC lines, which are sensitive to SnTox1, had mean lesion types of 4.0, 4.5, and 5.0 for the 5-, 7-, and 10-day readings, respectively, making them significantly $(P<0.05)$ different from N1BT1D and CS-DIC 1B (data not shown). Therefore, the toxin-sensitive lines were more susceptible to the Sn2000 fungus at the 5- and 7-day readings, but the difference was less obvious for the 10-day reading.

To determine the gene action of toxin sensitivity, we developed a population consisting of $120 \mathrm{~F}_{2}$ plants derived from crossing CS $\times$ CS-DIC 1B. Evaluation of reaction to the toxin indicated that the population segregated in a ratio of 93:27 sensitive/insensitive and fit the expected ratio of $3: 1\left(\chi^{2}=0.4 ; 0.75>P>0.50\right)$. This indicates that sensitivity to the toxin is dominantly inherited.

\section{DISCUSSION}

Most previous studies have suggested that resistance to $S$. nodorum is complex and controlled by multiple genes $(3,8,16$, $46,52)$. The results of our research agree with the results of previous studies in that resistance to $S$. nodorum is quantitatively inherited, but the toxin-insensitivity locus $(s n n l)$ underlies a major QTL and is responsible for a large portion of the phenotypic variation observed in this population.

Analysis of the CS aneuploid and RI lines indicated that toxinsensitive plants are more susceptible to the Sn2000 fungus than toxin-insensitive plants. This result and the progressive reduction in effect over time of the 1BS QTL detected by snnl indicate that SnTox 1 plays an important role in causing disease. Ptr ToxA, a necrosis-inducing toxin produced by Pyrenophora tritici-repentis, is also a proteinaceous HST, and insensitivity to the toxin is correlated with the resistance to the tan spot fungus $(5,24)$. However, Friesen et al. $(17,18)$ recently demonstrated that insensitivity to Ptr ToxA in the host does not result in complete resistance to tan spot. Their results suggest that Ptr ToxA is a virulence factor that is important for disease manifestation at 3 and 5 days postinoculation, but the toxin seems to play a nonsignificant role at 8 days postinoculation (17).

Our studies showed that, similar to Ptr ToxA, SnTox1 is especially important for causing disease in the early stages of the host-pathogen interaction. The toxin-insensitive aneuploid lines CS N1BT1D and CS-DIC 1B were less susceptible than CS and the other NT and CS-DIC substitution lines, but they were not resistant. Furthermore, Opata 85, which is toxin insensitive, was only moderately resistant to the fungus. These data suggest that SnTox 1 is also an important virulence factor for $\mathrm{Sn} 2000$, but not necessarily a pathogenicity factor because it is not required for disease development (44).

Another similarity between the systems involving Ptr ToxA and SnTox 1 is the fact that sensitivity to both toxins is dominant. Insensitivity to Ptr ToxA is conferred by the tsnl gene on the long arm of chromosome 5B (11). Anderson et al. (1) showed that insensitivity to Ptr ToxA also is conferred by the null allele, suggesting that the toxin requires a host gene product produced by 
the Tsn1 gene to manifest necrosis. Given the fact that the null condition of CS N1B T1D leads to SnTox1 insensitivity, SnTox1 mimics the Ptr ToxA system by requiring a host gene product for sensitivity.

Frecha (15) reported that the common wheat cv. Atlas 66 carried a dominant gene for resistance, and Kleijer et al. (23) used CS monosomic analysis to show that this gene resided on chromosome 1B. Frecha (15) reported that all $\mathrm{F}_{1}$ plants derived from the crosses between Atlas 66 and a susceptible line were resistant, and the $F_{2}$ populations segregated in a ratio of 3:1 resistant/susceptible, suggesting that Atlas 66 does contain a dominant gene for resistance. However, Kleijer et al. (23) reported observing no clear 3:1 segregation in the monosomic study and suggested that CS carries a gene on chromosome 1B that modifies the expression of the dominant resistance gene on chromosome 1B of Atlas 66. The modifying effects from CS may have been due to Snnl, and it is possible that the dominant gene in Atlas 66 is an allele of the toxin sensitivity gene, or that a different SNB resistance gene resides on chromosome 1B in Atlas 66. In preliminary experiments, we found Atlas 66 to be insensitive to SnTox 1 and highly resistant to fungal inoculations with Sn2000 having lesion types of 0 to 1 (data not shown). Further work, including the generation of appropriate populations and subsequent genetic analyses, is needed to determine the relationship of snnl with the resistance gene or genes in Atlas 66.

The $T$. dicoccoides accession used to create the disomic substitution lines in the CS background was resistant to Sn2000, but no CS-DIC substitution lines showed the same level of resistance as $T$. dicoccoides. Only CS-DIC 1B was less susceptible, presumably due to insensitivity to the toxin. There may be several genes with minor effects on different chromosomes that contribute to the resistance observed in $T$. dicoccoides, or the resistance genes in $T$. dicoccoides may not express properly in the CS background. Also, not all CS-DIC substitution lines are available (CSDIC $3 \mathrm{~A}$ and $6 \mathrm{~B}$ are missing), so there may be resistance factors present on the chromosomes that were not evaluated.

TABLE 3. Results of single-factor regression analysis of markers significantly associated with resistance to Stagonospora nodorum isolate Sn2000 at 5, 7, and 10 days postinoculation ${ }^{y}$

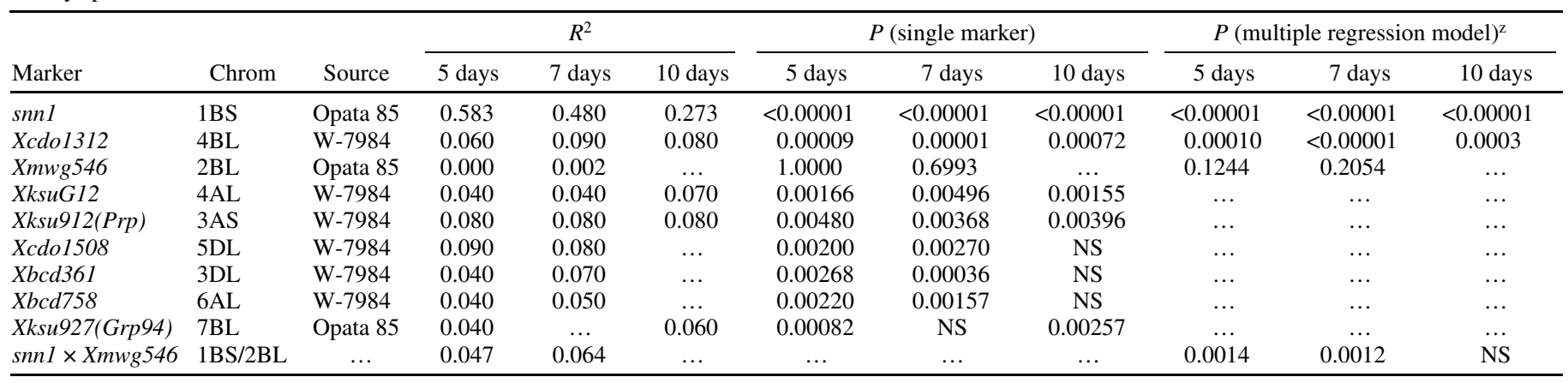

${ }^{y}$ Chrom $=$ chromosome, Source $=$ resistance source, $\mathrm{NS}=$ nonsignificant at the 0.005 level of probability.

${ }^{\mathrm{z}} R^{2}=0.682,0.622$, and 0.363 at 5,7 , and 10 days postinoculation, respectively.

\section{Chromosome 1B}

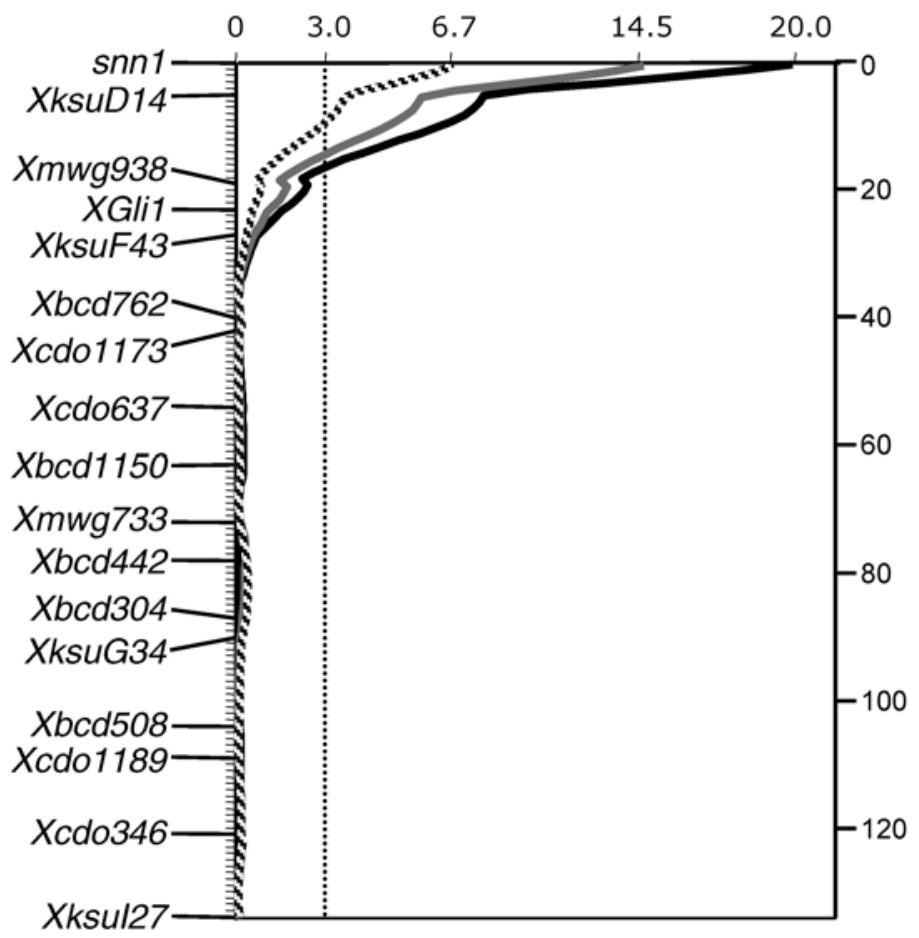

Chromosome 4B

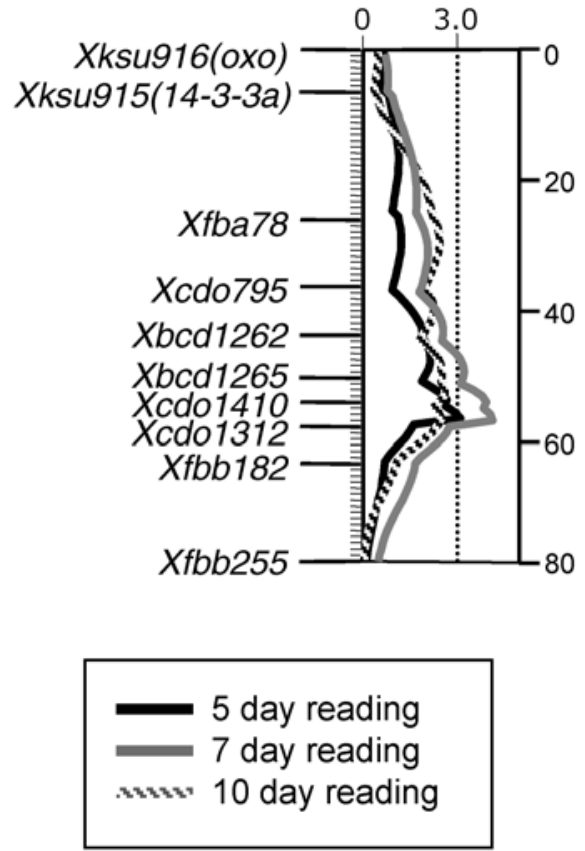

Fig. 3. Composite interval regression maps of chromosomes $1 \mathrm{~B}$ and $4 \mathrm{~B}$ indicating the association of snn1 with reaction to Sn2000 at 5, 7, and 10 days after inoculation. The dotted line represents the logarithm of the odds (LOD) significance threshold of 3.0. On the 1B map, the LOD values for the largest quantitative trait loci peaks are given along the top horizontal line. For the 4B map, the peak LOD values for the 5-, 7-, and 10-day readings are 3.34, 4.56, and 2.75, respectively. A centimorgan scale is indicated to the right of the graphs. 
In addition to the major QTL on the short arm of chromosome 1BS, we identified several relatively minor QTL on chromosomes 3AS, 3DL, 4AL, 4BL, 5DL, 6AL, and 7BL and an epistatic interaction. We also observed changes in the degrees of effects conferred by the minor QTL over time. The putative QTL on 3DL, 6AL, and 4BL detected by Xbcd361, Xbcd758, and Xcdo1312, respectively, and the epistatic interaction had increased resistance effects at 7 days compared with 5 days postinoculation, but they showed decreased effects at 10 days compared with 7 days after inoculation. Therefore, the genes underlying these QTL and the factors involved in the interaction may lie downstream of the recognition machinery in the defense response pathway.

No QTL had significant effects specific to the 10-day reading. Only the putative QTL on chromosomes 4AL and 7BL detected by XksuG12 and Xksu927(Grp94), respectively, showed an apparent increase in resistance effects at 10 days compared with 5 or 7 days postinoculation. It is possible that these loci represent, or are closely linked to, defense response genes which are known to act downstream of the pathogen recognition (20). It is interesting to note that there is a cluster of known defense response genes near Xksu927(Grp) on 7BL (27). Within this cluster, there are genes encoding a chitinase $(X k s u 928(C h i))$, two thaumatin-like proteins (Xksu917(Tha) and Xksu910(Tha)), a catalase gene (Xksu929(Cat)), and a Grp94 (ion channel regulator)-like protein $(X k s u 927(G r p))$. This cluster of defense response genes also has been shown to harbor a major QTL for durable leaf rust resistance in this population (13) and others $(9,53)$. However, it also is possible that these regions are spurious QTL detected by random chance due to the significance threshold used in this study. A much larger population evaluated in a large number of replications is needed to confirm the significance of these and the other minor QTL identified in this study. Nevertheless, with the exception of the snn1 locus on 1BS, it is apparent that the effects of nearly all minor QTL identified in this study peaked at 7 days postinoculation, which suggests that future studies should employ disease evaluations at 5 to 7 days after inoculation to maximize detection.

Three of the putative QTL identified in this research have the potential of being the same as previously identified QTL. The major QTL detected by the snnl gene on chromosome 1BS may be allelic to the gene in Atlas 66 identified by Frecha (15). Cao et al. (4) identified a gene ( $s n b T M)$ on chromosome $3 \mathrm{~A}$ in durum wheat that was introgressed from $T$. timopheevii, which may or may not be allelic to the gene underlying the minor QTL that we identified on chromosome 3AS. Most studies indicate that the inheritance of leaf blotch resistance is independent to that of glume blotch resistance, but the QTL we identified on $4 \mathrm{BL}$ is in a position very similar to QSng.sfr-4BL identified by Schnurbusch et al. (45) that conferred resistance to glume blotch. In their population, the $4 \mathrm{BL}$ QTL explained $\approx 19 \%$ of the phenotypic variation for glume blotch resistance. It is important to note that our study may differ from previous studies, in that we employed a single toxin-producing isolate of $S$. nodorum and evaluated juvenile plants for the reaction to SNB using a qualitative rating scale. The qualitative

TABLE 4. Lesion-type means of the four possible classifications of recombinant inbred (RI) lines for allelic state at snn1 and Xmwg546 for 5 and 7 days after inoculation of the International Triticeae Mapping Initiative population with Stagonospora nodorum isolate Sn2000

\begin{tabular}{lcccc}
\hline & & \multicolumn{2}{c}{ Lesion-type means $^{\mathrm{z}}$} \\
\cline { 4 - 5 } snn1 & Xmwg546 & No. of RI lines & 5 days & 7 days \\
\hline Opata 85 & Opata 85 & 29 & $1.74 \mathrm{a}$ & $1.98 \mathrm{a}$ \\
Opata 85 & W-7984 & 26 & $1.58 \mathrm{a}$ & $1.86 \mathrm{a}$ \\
W-7984 & Opata 85 & 30 & $2.60 \mathrm{~b}$ & $2.67 \mathrm{~b}$ \\
W-7984 & W-7984 & 18 & $3.09 \mathrm{c}$ & $3.22 \mathrm{c}$ \\
\hline
\end{tabular}

${ }^{\mathrm{z}}$ Numbers followed by the same letter within the same column are not significantly different at $P=0.05$ based on a least significant difference test. Lesion-types range from 0 (most resistant) to 5 (most susceptible). scale was developed based on other disease reaction scales $(14,25,50)$, using disease reaction type and lesion size. Because toxin-producing fungi have the ability to colonize tissue that has been killed in advance of the growing mycelium, lesion size and morphology are important aspects when measuring the resistance response. This qualitative scale measures the containment of the fungus after penetration of the host tissue and the effect that different host genes, including snnl, have on reduction of fungalinduced necrosis or chlorosis. This qualitative, numerical type scale has been used effectively in several other necrotrophic cereal pathosystems, including Pyrenophora tritici-repentis (25), P. teres (50), and Cochliobolus sativus (14). Other studies may have used different populations, isolates, or rating scales and evaluated adult plant leaves or glumes. These factors may lead to the identification of different QTL.

Both parents were moderately resistant to $\mathrm{Sn} 2000$, but transgressive segregants were common among the progeny. Wicki et al. (52) also found transgressive inheritance in populations derived from crosses between two moderately resistant parents. This suggests that transgression breeding can be used to develop cultivars highly resistant to SNB. The two largest resistance QTL identified in our research were derived from different parents, and the two parents showed different resistance mechanisms. Other research has led to the identification of resistance QTL which have chromosomal locations that differ from those identified in our research. It should be possible to combine resistance QTL from different sources for the development of wheat and durum cultivars that possess high levels of durable SNB resistance. The markers identified in this research to be associated with SNB resistance QTL should be useful for marker-assisted selection to develop Sn2000-resistant germ plasm. Alternatively, culture filtrates or partially purified toxin could be used to select for toxininsensitive plants, which would be at least partially resistant to SNB. However, other QTL necessary for more complete resistance would not be selected for. Furthermore, because of the dominance of toxin sensitivity, extensive progeny testing would be required when backcrossing to introgress the $s n n 1$ allele into a sensitive genotype because all $\mathrm{BC}_{1}$ progeny would be sensitive. This could be circumvented by selecting the heterozygous $\mathrm{BC}_{1}$ individuals with closely linked molecular markers and advancing them to subsequent rounds of backcrossing.

\section{ACKNOWLEDGMENTS}

This research was supported by USDA-ARS CRIS 5442-22000-03000D and 5442-21000-026-00D. We thank P. Meyer for technical assistance.

\section{LITERATURE CITED}

1. Anderson, J. A., Effertz, R. J., Faris, J. D., Francl, L. J., Meinhardt, S. W., and Gill, B. S. 1999. Genetic analysis of sensitivity to a Pyrenophora tritici-repentis necrosis-inducing toxin in durum and common wheat. Phytopathology 89:293-297.

2. Börner, A., Schumann, E., Fürste, A., Cöster, H., Leithold, B., Röder, M., and Weber, W. 2002. Mapping of quantitative trait loci determining agronomic important characters in hexaploid wheat (Triticum aestivum L). Theor. Appl. Genet. 105:921-936.

3. Bostwick, E. D., Ohm, H. W., and Shaner, G. 1993. Inheritance of Septoria nodorum blotch resistance in wheat. Crop Sci. 33:439-443.

4. Cao, W., Hughes, G. R., Ma, H., and Dong, Z. 2001. Identification of molecular markers for resistance to Septoria nodorum blotch in durum wheat. Theor. Appl. Genet. 102:551-554.

5. Ciuffetti, L. M., Tuori, R. P., and Gaventa, J. M. 1997. A single gene encodes a selective toxin causal to the development of tan spot of wheat. Plant Cell 9:135-144.

6. Cunfer, B. M., and Ueng, P. P. 1999. Taxonomy and identification of Septoria and Stagonospora species on small-grain cereals. Annu. Rev. Phytopathol. 37:267-284.

7. Czembor, P. C., Arseniuk, E., Czaplicki, A., Song, Q. J., Cregan, P. B., and Ueng, P. P. 2003. QTL mapping of partial resistance in winter wheat to Stagonospora nodorum blotch. Genome 46:546-554. 
8. Du, C. G., Nelson, L. R., and McDaniel, M. E. 1999. Diallel analysis of gene effects conditioning resistance to Stagonospora nodorum (Berk.) in wheat. Crop Sci. 39:686-690.

9. Eriksen, L., Borum, F., and Jahoor, A. 2003. Inheritance and localization of resistance to Mycosphaerella graminicola causing Septoria tritici blotch and plant height in the wheat (Triticum aestivum L) genome with DNA markers. Theor. Appl. Genet. 107:515-527.

10. Eyal, Z. 1999. Breeding for resistance to Septoria and Stagonospora disease of wheat. Pages 332-344 in: Septoria on Cereals-A Study of Pathosystems. J. A. Lucas, P. Bowyer, and H. M. Anderson, eds. IACRLong Ashton Research station, Bristol, UK.

11. Faris, J. D., Anderson, J. A., Francl, L. J., and Jordahl, J. G. 1996. Chromosomal location of a gene conditioning insensitivity in wheat to a necrosis-inducing culture filtrate from Pyrenophora tritici-repentis. Phytopathology 86:459-463.

12. Faris, J. D., Anderson, J. A., Francl, L. J., and Jordahl, J. G. 1997. RFLP mapping of resistance to chlorosis induction by Pyrenophora triticirepentis in wheat. Theor. Appl. Genet. 94:98-103.

13. Faris, J. D., Li, W. L., Liu, D. J., Chen, P. D., and Gill, B. S. 1999. Candidate gene analysis of quantitative disease resistance in wheat. Theor. Appl. Genet. 98:219-225.

14. Fetch, T. G., Jr., and Steffenson, B. J. 1999. Rating scales for assessing infection responses of barley infected with Cochliobolus sativus. Plant Dis. 83:213-217.

15. Frecha, J. H. 1973. The inheritance of resistance to Septoria nodorum in wheat. Bol. Genet. Inst. Fitotec. Castelar 8:29-30.

16. Fried, P. M., and Meister, E. 1987. Inheritance of leaf and head resistance of winter wheat to Septoria nodorum in a diallel cross. Phytopathology 77:1371-1375.

17. Friesen, T. L., Ali, S., Kianian, S., Francl, L. J., and Rasmussen, J. B. 2003. Role of host sensitivity to Ptr ToxA in development of tan spot of wheat. Phytopathology 93:397-401.

18. Friesen, T. L., Rasmussen, J. B., Kwon, C. Y., Ali, S., Francl, L. J., and Meinhardt, S. W. 2002. Reaction of Ptr ToxA-insensitive wheat mutants to Pyrenophora tritici-repentis race1. Phytopathology 92:38-42.

19. Haley, C. S., and Knott, S. A. 1992. A simple regression method for mapping quantitative trait loci in line cross using flanking markers. Heredity 69:315-324.

20. Hammond-Kosack, K. E., and Jones, J. D. G. 1996. Resistance genedependent plant defense responses. Plant Cell 8:1773-1791.

21. Khlestkina, E. K., Pestsova, E. G., Röder, M. S., and Börner, A. 2001. Molecular mapping, phenotypic expression and geographical distribution of genes determining anthocyanin pigmentation of coleoptiles in wheat (Triticum aestivum L.). Theor. Appl. Genet. 104:632-637.

22. King, J. E., Cook, R. J., and Melville, S. C. 1983. A review of Septoria diseases of wheat and barley. Ann. Appl. Biol. 103:345-373.

23. Kleijer, G., Bronnimann, A., and Fossati, A. 1977. Chromosomal location of a dominant gene for resistance at the seedling stage to Septoria nodorum Berk. in the wheat variety Atlas 66. Z. Pflanzenzuecht 78:170-173.

24. Lamari, L., and Bernier, C. C. 1989. Toxin of Pyrenophora triticirepentis: Host-specificity, significance in disease, and inheritance of host reaction. Phytopathology 79:740-744.

25. Lamari, L., and Bernier, C. C. 1989. Evaluation of wheat for reaction to tan spot (Pyrenophora tritici-repentis) based on lesion type. Can. J. Plant Pathol. 11:49-56.

26. Landers, E. S., and Botstein, D. 1989. Mapping Mendelian factors underlying quantitative traits using RFLP linkage maps. Genetics 121:185-199.

27. Li, W. L., Faris, J. D., Chittoor, J. M., Leach, J. E., Hulbert, S. H., Liu, D. J., Chen, P. D., and Gill, B. S. 1999. Genomic mapping of defense response genes in wheat. Theor. Appl. Genet. 98:226-233.

28. Liu, Z. H., Faris, J. D., Meinhardt, S. W., Ali, S., Rasmussen, J. B., and Friesen, T. L. 2004. Genetic and physical mapping of a gene conditioning sensitivity in wheat to a partially purified host-selective toxin produced by Stagonospora nodorum. Phytopathology 94:1056-1060.

29. Ma, H., and Hughes, G. R. 1995. Genetic control and chromosomal location of Triticum timopheevii derived resistance to Septoria nodorum blotch in durum wheat. Genome 38:332-338.

30. Manly, K. K., Cudmore, R. H., Jr., and Meer, J. M. 2001. Map Manager QTX, cross platform software for genetic mapping. Mam. Gen. 12:930-932.

31. Marino, C. L., Nelson, J. C., Lu, Y. H., Sorrells, M. E., Leroy, P., Tuleen, N. A., Lopes, C. R., and Hart, G. E. 1996. Molecular genetic maps of the group 6 chromosomes of hexaploid wheat (Triticum aestivum L. em Thell). Genome 39:3-366.

32. Mckendry, A. L., Henke, G. E., and Finney, P. L. 1995. Effects of Septoria leaf blotch on soft red winter wheat milling and baking quality. Cereal Chem. 72:142-146.

33. Messmer, M., Keller, M., Winzeler, M., Schachermayr, G., Feuillet, C., Gallego, F., Winzeler, H., and Keller, B. 1997 Identification of Quantitative Trait loci (QTL) for Septoria nodorum resistance in a wheat Spelt population. Page S12 in: Proc. Int. Triticeae Mapping Initiative (ITMI) Public Workshop. Clermont-Ferrand, France.

34. Mullaney, E. J., Martin, J. M., and Scharen, A. L. 1982. Generation mean analysis to identify and partition the components of genetic resistance to Septoria nodorum in wheat. Euphytica 31:539-545.

35. Murphy, N. E. A., Loughman, R., Wilson, R., Lagudah, E. S., Appels, R., and Jones, M. G. K. 2000. Resistance to Septoria nodorum blotch in the Aegilops tauschii accession RL5271 is controlled by a single gene. Euphytica 113:227-233.

36. Nelson, J. C. 1997. $Q$-GENE: Software for marker-based genomic analysis and breeding. Mol. Breed. 3:239-245.

37. Nelson, J. C., Autrique, J. E., Fuentes-Davila, G., and Sorrells, M. E. 1998. Chromosomal location of genes for resistance to Karnal bunt in wheat. Crop Sci. 38:231-236.

38. Nelson, J. C., Singh, R. P., Autrique, J. E., and Sorrells, M. E. 1997. Mapping genes conferring and suppressing leaf rust resistance in wheat. Crop Sci. 37:1928-1935.

39. Nelson, J. C., Sorrells, M. E., Van Deynze, A. E., Lu, Y. H., Atkinson, M., Bernard, M., Leroy, P., Faris, J. D., and Anderson, J. A. 1995. Molecular mapping of wheat: Major genes and rearrangements in homoeologous groups 4, 5, and 7. Genetics 141:721-731.

40. Nelson, J. C., Van Deynze, A. E., Autrique, E., Sorrells, M. E., Lu, Y. H., Merlino, M., Atkinson, M., and Leroy, P. 1995. Molecular mapping of wheat homoeologous group 2. Genome 38:516-524.

41. Nelson, J. C., Van Deynze, A. E., Autrique, E., Sorrells, M. E., Lu, Y. H., Negre, S., Bernard, M., and Leroy, P. 1995. Molecular mapping of wheat homoeologous group 3. Genome 38:525-533.

42. Nelson, L. R., and Gates, C. E. 1980. Inheritance of resistance to Septoria nodorum in wheat. Crop Sci. 20:447-449.

43. Röder, M. S., Korzun, V., Wendehake, K., Plaschke, J., Tixier, M. H., Leroy, P., and Ganal, M. W. 1998. A microsatellite map of wheat. Genetics 149:2007-2023.

44. Scheffer, R. P. 1983. Toxins as chemical determinants of disease. Pages 140 in: Toxins and Plant Pathogenesis. J. M. Daly and B. J. Deverall, eds. Academic Press, Australia.

45. Schnurbusch, T., Paillard, S., Fossati, D., Messmer, M., Schachermayr, G., Winzeler, M., and Keller, B. 2003. Detection of QTLs for Stagonospora glume blotch resistance in Swiss winter wheat. Theor. Appl. Genet. 107:1226-1234.

46. Scott, P. R., Benedikz, P. W., and Cox, C. J. 1982. A genetic study of relationship between height, time of ear emergence and resistance to Septoria nodorum in wheat. Plant Pathol. 31:45-60.

47. Sears, E. R. 1966. Nullisomic-tetrasomic combinations in hexaploid wheat. Pages 29-45 in: Chromosome Manipulations and Plant Genetics. R. Riley and K. R. Lewis, eds. Oliver and Boyd, London.

48. Singh, R. P., Nelson, J. C., and Sorrells, M. E. 2000. Mapping Yr28 and other genes for resistance to stripe rust in wheat. Crop Sci. 40:1148-1155.

49. Sourdille, P., Perretant, M. R., Charmet, G., Leroy, P., Gautier, M. F., Joudrier, P., Nelson, J. C., Sorrells, M. E., and Bernard, M. 1996. Linkage between RFLP markers and genes affecting kernel hardiness in wheat. Theor. Appl. Genet. 93:580-586.

50. Tekauz, A. 1985. A numerical scale to classify reactions of barley to Pyrenophora teres. Can. J. Plant Pathol. 7:170-177.

51. Van Deynze, A. E., Dubcovsky, J., Gill, K. S., Nelson, J. C., Sorrells, M. E., Dvorak, J., Gill, B. S., Lagudah, E. S., McCouch, S. R., and Appels, R. 1995. Molecular-genetic maps for group 1 chromosomes of Triticeae species and their relation to chromosomes in rice and oat. Genome 38:4559.

52. Wicki, W., Winzeler, M., Schmid, J. E., Stamp, P., and Messmer, M. 1999. Inheritance of resistance to leaf and glume blotch caused by Septoria nodorum Berk. in winter wheat. Theor. Appl. Genet. 99:1265-1272.

53. Williams, H. M., Hoisington, D., Singh, R. P., and González-de-Leon, D. 1997. Detection of quantitative trait loci associated with leaf rust resistance in bread wheat. Genome 40:253-260. 